\title{
Desempenho, características de carcaça e viabilidade econômica de coelhos sexados abatidos em diferentes idades
}

[Performance, carcass characteristics and economic viability of sexed rabbits slaughtered at different ages]

\author{
M.C. Oliveira ${ }^{1}$, J.F. $L u i^{2}$ \\ ${ }^{1}$ Universidade de Rio Verde \\ Caixa Postal 104 \\ 75901-970 - Rio Verde, GO \\ ${ }^{2}$ Universidade Estadual Paulista - UNESP - Jaboticabal, SP
}

\begin{abstract}
RESUMO
Avaliaram-se o desempenho, as características de carcaça e a viabilidade econômica de coelhos sexados abatidos em diferentes idades. Foram usados 100 coelhos (50 machos e 50 fêmeas), em delineamento de blocos inteiramente ao acaso e arranjo fatorial $2 \times 2$ (dois sexos e duas idades ao abate), com quatro tratamentos e cinco repetições. Os coelhos foram desmamados aos 35 e abatidos aos 75 ou 90 dias de idade. Não houve diferença entre sexo $(\mathrm{P}>0,05)$ nos parâmetros avaliados. Os animais abatidos aos 90 dias $(\mathrm{P}<0,001)$ eram mais pesados e consumiram (diário) mais ração. Os abatidos aos 75 dias $(\mathrm{P}<0,001)$ ganharam mais peso (diário) e apresentaram melhor conversão alimentar. Coelhos abatidos aos 90 dias de idade tiveram maiores pesos relativos de carcaça $(\mathrm{P}<0,04)$, de coxa $(\mathrm{P}<0,001)$, de gordura interna $(\mathrm{P}<0,001)$ e de fígado $(\mathrm{P}<0,01)$ e, ainda, apresentaram maior peso final e melhores características de carcaça, cuja venda foi mais lucrativa quando realizada aos 75 dias ou quando foram abatidos aos 90 dias de idade.
\end{abstract}

Palavras-chave: coelho, ganho de peso, rendimento de carcaça

\begin{abstract}
Performance, carcass characteristics and economic viability of sexed rabbits slaughtered at different ages were evaluated. One-hundred rabbits (50 males and 50 females) were assigned to a completely randomized block design in a factorial arrangement of $2 \times 2$ (two sexes and two slaughter ages), with four treatments and five replicates. The rabbits weaned at 35 were slaughtered at 75 and 90 days of age. No effect of sex $(P>0.05)$ on the evaluated parameters was observed. Animals slaughtered at 90 days were heavier $(P<0.001)$, had a higher daily feed intake and a higher carcass weight than animals slaughtered at 75 days which showed higher daily weight gain and better feed: gain ratio. Rabbits slaughtered at 90 days of age had higher carcass weight $(P<0.04)$, thigh $(P<0.005)$, internal fat $(P<0.001)$ and liver $(P<0.01)$. They also showed better carcass characteristics. High rentability was obtained alternatively for animals sold alive at 25 days of age or slaughtered at 90 days of age.
\end{abstract}

Keyword: rabbit, weight gain, carcass yield

Recebido em 22 de agosto de 2005

Aceito em 14 de junho de 2006

Autor para correspondência (corresponding author)

E-mail: cristina@fesurv.br 


\section{INTRODUÇÃO}

O aumento no peso ao abate dos coelhos pode ser alcançado utilizando-se linhagens para maior peso ou atrasando a idade ao abate. $\mathrm{O}$ sexo dos coelhos não é, normalmente, um fator influente no desempenho produtivo dos animais em crescimento. Já o aumento da idade ao abate permite que o animal alcance maior peso corporal, mas o aumento do consumo de ração e a piora na conversão alimentar reduzem o interesse econômico em criar coelhos até uma idade mais avançada (Luzi et al., 2000). Entretanto, o aumento no custo de produção poderia ser contrabalanceado pelos maiores preços de venda garantidos a produtos com melhores qualidades técnicas e organolépticas já que se acredita que o atraso da idade ao abate melhora a qualidade da carne do coelho (Gondret et al., 1998).

Com relação à qualidade da carcaça, vários fatores podem influenciá-la, tais como temperatura e umidade do ambiente e estação do ano (Paci et al., 1999), fatores que modifiquem o metabolismo muscular (Dalle Zotte et al., 1996), sexo (Russo et al., 1998), tipo de criação (Dal Bosco et al., 2000) e idade ao abate (Cavani et al., 2000).

Coelhos mais velhos e mais pesados têm maior teor de gordura perirrenal e muscular que os mais jovens e mais leves. Isso significa que eles são mais maduros. Essa maturidade está associada com o aumento do metabolismo glicolítico e baixo $\mathrm{pH}$ e maior capacidade de retenção de água da carne (Ouhayoun, 1998).

Rao et al. (1978) e Deltoro e López (1986) relataram que os rendimentos de carcaça e de coxa aumentaram com o aumento da idade ao abate, porém, não observaram diferenças nos rendimentos de fígado, rins e coração. Szendrö et al. (1998b) também observaram um melhor rendimento de carcaça de coelhos abatidos aos 95 dias $(60,6 \%)$ comparado com aqueles abatidos aos 74 dias de idade $(58,8 \%)$. Os depósitos de gordura também podem ser maiores em coelhos abatidos mais tardiamente (Gondret et al., 1998) e em fêmeas (Deltoro e López, 1986). Segundo Parigi-Bini et al. (1992), fêmeas tendem a apresentar menor rendimento de carcaça e menor razão carne/osso quando abatidas em diferentes idades $(62,69,76,83$ e 90 dias de idade).

Ao avaliarem os efeitos da idade ao abate (75 e 90 dias) e do sexo sobre características da carcaça, Bernardini et al. (1995) verificaram melhor rendimento de carcaça, maior teor de gordura perirrenal e maior razão carne/osso em animais abatidos aos 90 dias, e que o sexo influenciou somente o peso relativo da cabeça, sendo este valor maior para os machos. Dalle Zotte et al. (1996) não detectaram efeito do sexo sobre o peso ao abate dos animais, mas verificaram que os coelhos abatidos mais tardiamente (87 dias) eram mais pesados do que aqueles abatidos mais novos (57 e 80 dias de idade).

Este experimento foi realizado para avaliar o desempenho, as características de carcaça e a viabilidade econômica de coelhos sexados abatidos em diferentes idades.

\section{MATERIAL E MÉTODOS}

O experimento, realizado de janeiro a maio de 2002, utilizou 100 coelhos da raça Nova Zelândia Branco (50 machos e 50 fêmeas) com peso inicial médio de $816,50 \pm 43,23 \mathrm{~g}$, desmamados com 35 dias e abatidos aos 75 e 90 dias de idade. $\mathrm{O}$ delineamento experimental foi em blocos inteiramente ao acaso, em arranjo fatorial $2 \times 2$ (dois sexos e duas idades ao abate) totalizando quatro tratamentos com cinco repetições.

O sistema de criação foi ao ar livre, com animais mantidos, em número de cinco, em gaiolas com laterais de alvenaria, medindo $0,80 \mathrm{~m} \times 0,75 \mathrm{~m} \times$ $0,67 \mathrm{~m}$ (comprimento $\times$ largura $\times$ altura), dotadas de comedouro e bebedouro, ambos de cerâmica. A água e a ração comercial peletizada (Tab. 1) foram fornecidas à vontade.

Os animais e as rações foram pesados no início e no final do experimento para cálculos do ganho de peso e do consumo diário de ração e da conversão alimentar. Em seguida à pesagem final, os animais foram submetidos a jejum alimentar de 12 horas e, após esse período, foram novamente pesados para obtenção do peso ao abate que serviu de referência para o cálculo do peso relativo da carcaça. Após evisceração, 
foram retirados a cabeça e os pés, obtendo-se a carcaça que foi pesada 15 minutos após o abate $\mathrm{e}$, posteriormente, vísceras comestíveis e gordura interna foram pesadas e seus pesos relativos determinados em relação ao peso ao abate.

Tabela 1. Níveis mínimos de garantia da ração peletizada comercial $^{1,2}$ oferecida a coelhos em crescimento

\begin{tabular}{|c|c|}
\hline Nutriente & Nível \\
\hline Matéria seca (\%) & 88,00 \\
\hline Proteína bruta $(\%)$ & 17,00 \\
\hline Extrato etéreo (\%) & 3,37 \\
\hline Fibra bruta (\%) & 15,00 \\
\hline Matéria mineral (\%) & 12,00 \\
\hline Cálcio (\%) & 2,00 \\
\hline Fósforo total (\%) & 0,75 \\
\hline Lisina $(\%)$ & 0,94 \\
\hline Metionina + cistina $(\%)$ & 0,63 \\
\hline Energia digestível (kcal/kg) & 2.300 \\
\hline \multicolumn{2}{|c|}{$\begin{array}{l}{ }^{1} \mathrm{Na} \text { matéria natural. } \\
{ }^{2} \text { Enriquecimento por quilograma: } 8000 \text { UI de vitamina } \mathrm{A} \text {, } \\
1000 \mathrm{UI} \text { de vitamina } \mathrm{D}_{3} \text {, } 15 \mathrm{UI} \text { de vitamina } \mathrm{E}, 1,50 \mathrm{mg} \text { de } \\
\text { vitamina } \mathrm{K}_{3}, 2 \mathrm{mg} \text { de vitamina } \mathrm{B}_{1}, 5 \mathrm{mg} \text { de vitamina } \mathrm{B}_{2}, 2 \mathrm{mg} \\
\text { de vitamina } \mathrm{B}_{6}, 10 \mathrm{mcg} \text { de vitamina } \mathrm{B}_{12}, 1 \mathrm{mg} \text { de ácido fólico, } \\
18 \mathrm{mg} \text { de ácido pantotênico, } 35 \mathrm{mg} \text { de ácido nicotínico, } 500 \mathrm{mg} \\
\text { de colina, } 1,50 \mathrm{mg} \text { de } \mathrm{Co}, 6 \mathrm{mg} \mathrm{de} \mathrm{Cu}, 50 \mathrm{mg} \text { de } \mathrm{Zn}, 0,30 \mathrm{mg} \mathrm{de} \\
\mathrm{I} \text {, } 40 \mathrm{mg} \text { de Fe, } 40 \mathrm{mg} \text { de } \mathrm{Mn}, 0,10 \mathrm{mg} \text { de Se, } 10 \mathrm{mg} \text { de } \\
\text { promotor de crescimento e } 125 \mathrm{mg} \text { de antioxidante. }\end{array}$} \\
\hline
\end{tabular}

As patas traseiras foram retiradas, pesadas e dissecadas de acordo com a metodologia descrita por Blasco e Ouhayoun (1996) e a pata direita foi usada para obtenção da relação carne/osso de acordo com a fórmula $\mathrm{RC} / \mathrm{O}=\frac{\mathrm{PCa}}{\mathrm{PO}}$, em que RC/O é a relação carne/osso, PCa é o peso da carne (g) e PO é o peso dos ossos (g) (Rao et al., 1978).

Retirou-se, também, uma parte (aproximadamente $10 \mathrm{~cm}$ ) do músculo Longissimus dorsi, a qual foi levada ao forno elétrico à temperatura de $200^{\circ} \mathrm{C}$ por 30 minutos. Desligou-se o forno e, após 30 minutos, pesou-se o músculo e calcularam-se as perdas devido ao cozimento usando-se a fórmula $\mathrm{PCo}=\frac{\mathrm{Pm}_{\text {cru }}-\mathrm{PM}_{\text {cozida }}}{\mathrm{PM}_{\text {cru }}} \times 100$, em que PCo é a perda de peso pelo cozimento $(\%), \mathrm{PM}_{\text {cru }}$ é o peso da carne crua e $\mathrm{PM}_{\text {cozida }}$ é o peso da carne cozida (Piles et al., 2000).
A viabilidade econômica foi calculada considerando-se os valores médios de venda do coelho vivo para abate ( $\mathrm{R} \$ 4,00 / \mathrm{kg})$, do coelho abatido (R\$10,50/kg) e o valor da ração $(\mathrm{R} \$ 0,60 / \mathrm{kg})$. A margem bruta foi obtida pela diferença entre o lucro bruto (peso do animal vivo x $\mathrm{R} \$ 4,00$ ou peso da carcaça $\mathrm{x} \mathrm{R} \$ 10,50)$ e o custo da ração (peso da ração consumida $\mathrm{x}$ $\mathrm{R} \$ 0,60)$. Estes valores médios, pagos ao cunicultor, foram obtidos na Associação Paulista de Criadores de Coelhos em agosto de 2005.

Para a análise estatística usou-se o programa SAEG (Sistema...1997) e para a comparação de médias, o teste Tukey.

\section{RESULTADOS E DISCUSSÃO}

O sexo não influenciou $(\mathrm{P}>0,05)$ nenhum dos parâmetros avaliados (Tab. 2). Na maioria das espécies, os machos têm potencial de crescimento maior que as fêmeas. Entretanto em coelhos essa diferença não é importante pelo fato de serem abatidos antes da maturidade sexual, quando as diferenças se tornariam mais marcantes, devido à ação dos hormônios, e quando os machos poderiam crescer mais que as fêmeas (Ouhayoun, 1998; Ortiz Hernandez e Rubio Lozano, 2001).

Houve aumento no peso final e no consumo de ração, redução do ganho diário de peso e piora na conversão alimentar com o aumento da idade ao abate $(\mathrm{P}<0,001)$. Isso ocorreu provavelmente devido ao metabolismo, que fica mais lento à medida que o animal se torna mais velho, isto é, ganhe menos peso e acumule gordura. De acordo com Dalle Zotte (2002), o crescimento alométrico do tecido adiposo tende a aumentar com a idade. Os animais abatidos com 75 dias de idade tiveram ganho diário de peso $16,7 \%$ maior que os abatidos aos 90 dias, em virtude de os abatidos naquela idade estarem em fase de crescimento e exibirem melhor eficiência no uso dos nutrientes ingeridos, transformando-os em massa muscular. Aumento no peso final com redução no ganho de peso diário e menor consumo de ração associado à melhor conversão alimentar devido ao aumento da idade ao abate foram descritos por Bernardini et al. (1995) e Luzi et al. (2000), independente do sexo dos animais. 
Os animais abatidos aos 90 dias de idade apresentaram maiores pesos relativos de carcaça $(\mathrm{P}<0,04)$, de coxa $(\mathrm{P}<0,001)$ e de gordura interna $(\mathrm{P}<0,001) \quad$ (Tab. 3). A gordura apresenta crescimento alométrico progressivo, ao contrário do trato gastrintestinal e do esqueleto os quais têm crescimento desacelerado com o aumento da idade. Isso provoca aumento no rendimento de carcaça com o aumento da idade ao abate. Segundo Dalle Zoote (2002), o rendimento ao abate aumenta até o animal atingir 91 ou 98 dias de idade.

Tabela 2. Desempenho de coelhos sexados abatidos em diferentes idades

\begin{tabular}{|c|c|c|c|c|c|}
\hline \multirow{2}{*}{ Característica } & \multirow{2}{*}{ Sexo } & \multicolumn{2}{|c|}{ Idade ao abate (dias) } & \multirow{2}{*}{ Média } & \multirow{2}{*}{$\begin{array}{c}\text { Coeficiente de } \\
\text { variação (\%) }\end{array}$} \\
\hline & & 75 & 90 & & \\
\hline \multirow{3}{*}{ Peso final (kg) } & Macho & 2,31 & 2,57 & 2,44 & \\
\hline & Fêmea & 2,32 & 2,61 & 2,46 & \\
\hline & Média & $2,32 \mathrm{~b}$ & $2,59 \mathrm{a}$ & & 4,10 \\
\hline \multirow{3}{*}{$\begin{array}{l}\text { Ganho de peso } \\
\text { diário }(\mathrm{g} / \mathrm{d})\end{array}$} & Macho & 37,37 & 31,82 & 34,59 & \\
\hline & Fêmea & 37,54 & 32,75 & 35,14 & \\
\hline & Média & $37,45 \mathrm{a}$ & $32,28 b$ & & 5,83 \\
\hline \multirow{3}{*}{$\begin{array}{l}\text { Consumo de } \\
\text { ração diário }(\mathrm{g} / \mathrm{d})\end{array}$} & Macho & 101,02 & 117,45 & 109,24 & \\
\hline & Fêmea & 107,46 & 114,66 & 111,06 & \\
\hline & Média & $104,24 b$ & $116,06 a$ & & 3,16 \\
\hline \multirow{3}{*}{$\begin{array}{l}\text { Conversão } \\
\text { alimentar }\end{array}$} & Macho & 2,71 & 3,69 & 3,20 & \\
\hline & Fêmea & 2,87 & 3,53 & 3,20 & \\
\hline & Média & $2,79 b$ & $3,61 \mathrm{a}$ & & 8,17 \\
\hline
\end{tabular}

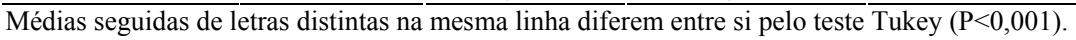

Tabela 3. Características de carcaça de coelhos sexados abatidos em diferentes idades

\begin{tabular}{|c|c|c|c|c|c|}
\hline \multirow{2}{*}{ Característica } & \multirow{2}{*}{ Sexo } & \multicolumn{2}{|c|}{ Idade ao abate (dias) } & \multirow{2}{*}{ Média } & \multirow{2}{*}{$\begin{array}{c}\text { Coeficiente de } \\
\text { variação }(\%)\end{array}$} \\
\hline & & 75 & 90 & & \\
\hline \multirow{4}{*}{ Carcaça } & \multicolumn{5}{|c|}{ Peso relativo (\%) } \\
\hline & Macho & 53,92 & 55,53 & 54,73 & \multirow[b]{3}{*}{5,38} \\
\hline & Fêmea & 53,11 & 57,92 & 55,52 & \\
\hline & Média & $53,52 b$ & $56,73 \mathrm{a}$ & & \\
\hline \multirow{3}{*}{ Coxa } & Macho & 15,09 & 18,75 & 16,92 & \multirow[b]{3}{*}{7,70} \\
\hline & Fêmea & 16,12 & 19,54 & 17,83 & \\
\hline & Média & $15,61 \mathrm{~b}$ & $19,15 \mathrm{a}$ & & \\
\hline \multirow{3}{*}{ Gordura interna } & Macho & 1,97 & 2,26 & 2,12 & \multirow[b]{3}{*}{6,71} \\
\hline & Fêmea & 1,82 & 2,23 & 2,03 & \\
\hline & Média & $1,89 \mathrm{~b}$ & $2,25 \mathrm{a}$ & & \\
\hline \multirow{3}{*}{ Rins } & Macho & 0,29 & 0,31 & 0,31 & \multirow[b]{3}{*}{7,73} \\
\hline & Fêmea & 0,33 & 0,33 & 0,33 & \\
\hline & Média & 0,31 & 0,32 & & \\
\hline \multirow{3}{*}{ Coração } & Macho & 0,27 & 0,28 & 0,27 & \multirow[b]{3}{*}{7,87} \\
\hline & Fêmea & 0,28 & 0,30 & 0,29 & \\
\hline & Média & 0,27 & 0,29 & & \\
\hline \multirow{3}{*}{ Fígado } & Macho & 2,33 & 2,53 & 2,43 & \multirow[b]{3}{*}{7,81} \\
\hline & Fêmea & 2,41 & 2,78 & 2,59 & \\
\hline & Média & $2,37 \mathrm{~b}$ & $2,66 \mathrm{a}$ & & \\
\hline
\end{tabular}

Médias seguidas de letras distintas na mesma linha diferem entre si pelo teste Tukey $(\mathrm{P}<0,04)$.

Aumento dos pesos relativos da carcaça, da coxa e da gordura interna devido ao aumento da idade ao abate foi demonstrado por Szendrö et al. (2002) e Combes et al. (2000). Em relação ao sexo dos animais, os resultados foram semelhantes aos de Ortiz Hernández e Rubio Lozano (2001) que não verificaram diferenças nos pesos relativos da carcaça e da gordura 
interna entre machos e fêmeas, abatidos com 80 dias de idade. Bernardini et al. (1995) não observaram melhor rendimento de coxa devido ao aumento da idade de abate de 75 para 90 dias, e Szendrö et al. (1998a) não verificaram diferença entre os sexos para o peso relativo da coxa.

Em relação ao peso das vísceras (Tab. 3), não houve diferença $(\mathrm{P}>0,05)$ quanto ao sexo para o fígado, o coração e os rins. $\mathrm{O}$ peso do fígado $(\mathrm{P}<0,01)$ dos animais abatidos aos 90 dias de idade foi superior, pois esse órgão aumenta de tamanho na medida em que o animal fica mais velho, fato esse já relatado por Rao et al. (1978).
Luzi et al. (2000) não observaram diferenças quanto ao peso de fígado em animais abatidos em diferentes idades.

Os animais abatidos aos 90 dias de idade apresentaram maior $(\mathrm{P}<0,001)$ relação carne/osso (Tab. 4), o que já era esperado em virtude de haver aumento na produção de carne (maior deposição protéica) com o aumento da idade, em contraste com o que ocorre com o esqueleto, que nessa idade já está formado e não tem mais crescimento progressivo. $\mathrm{O}$ aumento dessa relação devido ao abate tardio foi demonstrado por Rao et al. (1978) e Bernardini et al. (1995).

Tabela 4. Relação carne/osso e perdas no cozimento da carne de coelhos sexados abatidos em diferentes idades

\begin{tabular}{|c|c|c|c|c|c|}
\hline \multirow{2}{*}{ Característica } & \multirow{2}{*}{ Sexo } & \multicolumn{2}{|c|}{ Idade ao abate (dias) } & \multirow{2}{*}{ Média } & \multirow{2}{*}{$\begin{array}{c}\text { Coeficiente de } \\
\text { variação }(\%)\end{array}$} \\
\hline & & 75 & 90 & & \\
\hline \multirow{3}{*}{ Relação carne/osso } & Macho & 6,47 & 7,75 & 7,11 & \\
\hline & Fêmea & 6,47 & 8,10 & 7,28 & \\
\hline & Média & $6,47 b$ & $7,92 \mathrm{a}$ & & 8,98 \\
\hline \multirow{3}{*}{ Perdas no cozimento $(\%)$} & Macho & 27,47 & 27,21 & 27,34 & \\
\hline & Fêmea & 27,64 & 26,57 & 27,11 & \\
\hline & Média & 27,56 & 26,89 & & 9,91 \\
\hline
\end{tabular}

Médias seguidas de letras distintas na mesma linha diferem entre si pelo teste Tukey $(\mathrm{P}<0,001)$.

As perdas no cozimento vão determinar o grau de maciez e suculência da carne. Quanto maiores as perdas, menor a maciez e mais seca a carne. Neste experimento, não foram detectadas diferenças quanto às perdas no cozimento devido ao sexo ou à idade ao abate dos animais. Cavani et al. (2000) já haviam mencionado não haver diferenças quanto ao sexo e/ou idade ao abate com relação às perdas no cozimento. Combes et al. (2000) verificaram que as perdas no cozimento foram mais altas para coelhos abatidos aos 70 dias quando comparados com os abatidos aos 45 dias de idade e Ortiz Hernández e Rubio Lozano (2001) relataram maior perda durante o cozimento para machos.

Como não houve diferenças atribuídas ao sexo, esse fator não foi considerado na análise econômica. As maiores margens brutas (Tab. 5) foram de $\mathrm{R} \$ 6,76$ e $\mathrm{R} \$ 10,92$ para animais vendidos vivos aos 75 dias de idade e abatidos aos 90 dias, respectivamente. A margem bruta da venda de coelhos vivos foi maior em 4,2\% quando a venda ocorreu aos 75 dias e aumentou em 9,4\% com a venda de coelhos abatidos aos 90 dias, comparado à venda aos 90 e 75 dias, respectivamente. Esses resultados ocorreram porque, no animal vivo, o crescimento alométrico do tecido gorduroso aumenta com a idade, e o crescimento alométrico de outros tecidos e órgãos diminui, havendo aumento dos custos de alimentação associado ao rápido aumento do peso relativo da gordura em animais com peso corporal acima de $2,1 \mathrm{~kg}$ (Dalle Zotte, 2002). No caso dos animais abatidos, a maior margem bruta está associada à maior relação carne/osso observada nestes animais. 
Tabela 5. Viabilidade econômica do desempenho produtivo de coelhos sexados abatidos em diferentes idades

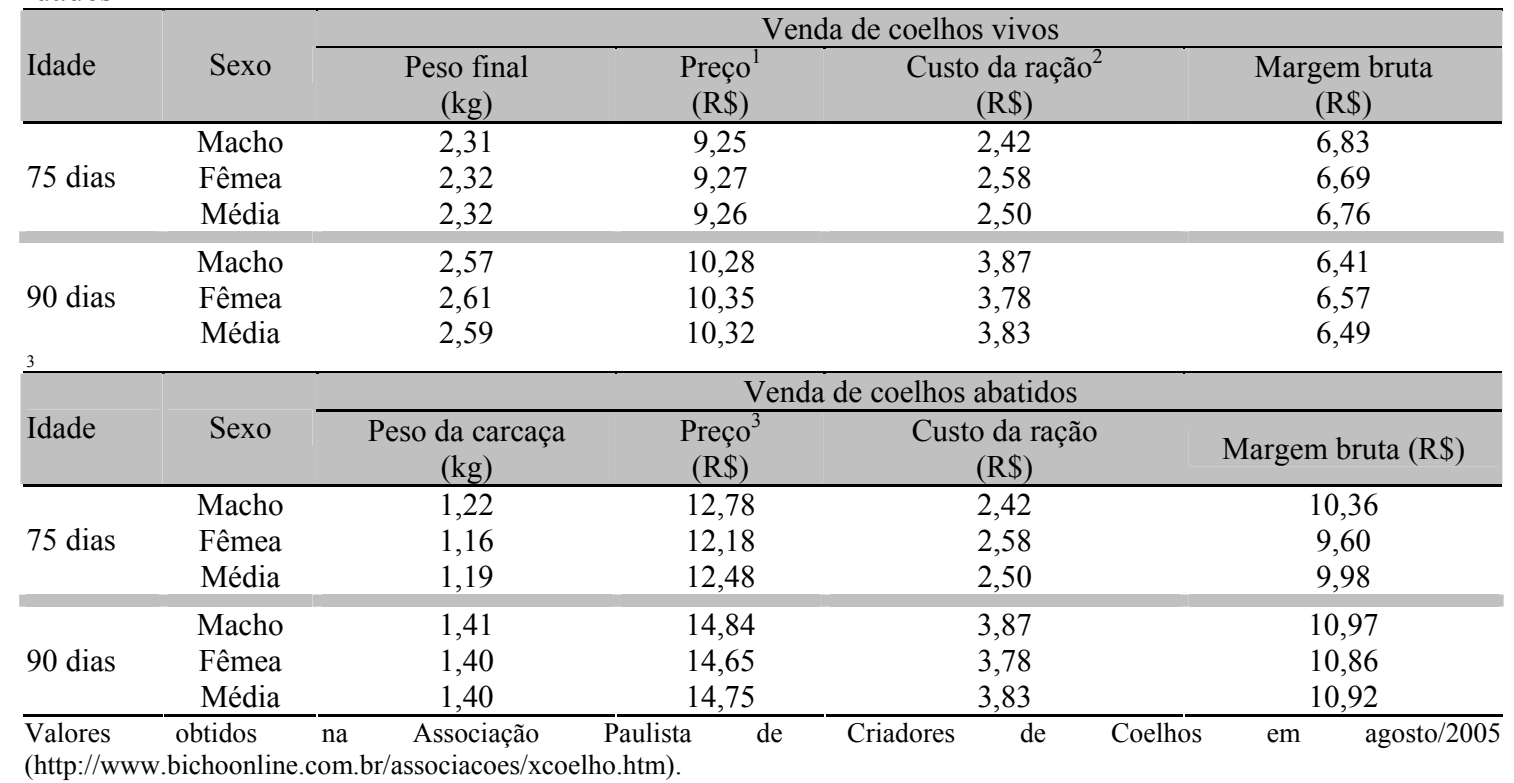

\section{CONCLUSÕES}

A criação de coelhos sexados não trouxe benefícios ao desempenho dos animais. Eles devem ser criados até 75 dias de idade caso sejam comercializados vivos, ou até os 90 , caso sejam abatidos.

\section{REFERÊNCIAS BIBLIOGRÁFICAS}

BERNARDINI, M.B.; CASTELLINI, C.; LATTAIOLI, P. Effect of sire strain, feeding, age and sex on rabbit carcass. World Rabbit Sci., v.3, p.9-14, 1995.

BLASCO, A.; OUHAYOUN, J. Harmonization of criteria and terminology in rabbit meat research. Revised proposal. World Rabbit Sci., v.4, p.93-99, 1996.

CAVANI, C.; BIANCHI, M.; LAZZARONI, C. et al. Influence of type of rearing, slaughter age and sex on fattening rabbit: II. Meat quality. World Rabbit Sci., v.8, p.567-572, 2000.

COMBES, S.; CHARLES, L.; AUVERGNE, A. et al. Evolution avec l'age des caracteristiques mecaniques des os en relation avec la qualitè bouchere des carcasses de lapin. In: JOURNÉES DES SCIENCES DU MUSCLE \& TECHNOLOGIE DE LA VIANDE, 8., 2000,
Paris. Proceedings... Paris: CTSCCV, 2000. p.39-42. (Resumo).

DAL BOSCO, A.; CASTELlinI, C.; BERNARDINI, M. Productive performance and carcass and meat characteristics of cage-or penraised rabbits. World Rabbit Sci., v.8, p.579-583, 2000.

DALLE ZOTTE, A. Perception of rabbit meat quality and major factors influencing the rabbit carcass and meat quality. Livest. Prod. Sci., v.75, p.11-32, 2002.

DALLE ZOTTE, A.; OUHAYOUN, J.; PARIGIBINI, R. et al. Effect of age, diet and sex on muscle energy metabolism and on related physicochemical traits in the rabbit. Meat Sci., v.43, p.15-24, 1996.

DELTORO, J.; LÓPEZ, A.M. Development of commercial characteristics of rabbit carcasses during growth. Livest. Prod. Sci., v.15, p.271283, 1986.

GONDRET, F.; MOUROT, J.; BONNEAU, M. Comparison of intramuscular adipose tissue cellularity in muscles differing in their lipid content and fibre type composition during rabbit growth. Livest. Prod. Sci., v.54, p.1-10, 1998.

LUZI, F.; LAZZARONI, C.; BARBIERI, S. et al. Influence of type of rearing, slaughter age and 
sex on fattening rabbit: I. Productive performance. World Rabbit Sci., v.8, p.613-619, 2000.

ORTIZ HERNÁNDEZ, J.A.; RUBIO LOZANO, M.S. Effect of breed and sex on rabbit carcass yield and meat quality. World Rabbit Sci., v.9, p.51-55, 2001.

OUHAYOUN, J. Influence of the diet on rabbit meat quality. In: BLAS, C.; WISEMAN, J. The nutrition of the rabbit. Madri: UPV, 1998. p.177195.

PACI, G.; COSSATO, M.M.F.; PILONI, S. et al. Effetto della stagione e della tecnica di allevamento sulle prestazioni produttive e sulla qualità della carne di coniglio. Riv. Coniglicolt., n.9, p.30-36, 1999.

PARIGI-BINI, R.; XICCATO, G.; CINETO, M. et al. Effetto dell'età, del peso di macellazione e del sesso sulla qualità della carcassa e della carne cunicola. I. rilievi di macelazione e qualità della carcassa. Zootec. Nutr. Anim., v.18, p.157-172, 1992.

PILES, M.; BLASCO, A.; PLA, M. The effect of selection for growth rate on carcass composition and meat characteristics of rabbit. Meat Sci., v.54, p.347-355, 2000.

RAO, D.R.; CHEN, C.P.; SUNKI, G.R. et al. Effect of weaning and slaughter ages on rabbit meat production.II. carcass quality and composition. J. Anim. Sci., v.46, p.578-583, 1978.

RUSSO, C.; PREZIUSO, G.; PACI, G.; CAMPODONI, G. et al. Effetto della linea paterna, dell'età di macellazione e del sesso sul profilo acidico della carne di coniglio. Riv. Coniglicolt., n.1, p.29-32, 1998.

SISTEMA de análises estatísticas e genéticas SAEG. Manual do usuário. Viçosa, MG: UFV, 1997. 59p.

SZENDRÖ, Z.S.; KENESSEY, A.; JENSEN, J.F. et al. Effect of genotype, age, body weight and sex on the body composition of growing rabbits. World Rabbit Sci., v.6, p.277-284, 1998a.

SZENDRÖ, Z.S.; ODERMATT, M.; METZER, S.Z. et al. Effect of age and body weight on some slaughter parameters of growing rabbits. In: RABBIT CONGRESS OF THE AMERICA, 2., 2002, Havana. Proceedings... Havana: Universidad de Cuba, 2002. p.242-245.

SZENDRÕ, Z.S.; RADNAI, I.; BIRÓNÉMETH, E. et al. The effect of live weight on the carcass traits and the chemical composition of meat of pannon white rabbits between 2.2 and $3.5 \mathrm{~kg}$. World Rabbit Sci., v.6, p. 243-250, 1998 b. 